\title{
The Practice of Grassroots League Construction in Higher Vocational Colleges from the Media Age
}

\author{
Cai Niekui \\ Yunnan Vocational College of Culture and Art, Kunming, Yunnan, 650111
}

Keywords: self media era; higher vocational colleges; grassroots league construction

\begin{abstract}
With the development of Internet information technology, the era of self media has come quietly. Under such circumstances, the ideas and values of the Youth League members have also been affected by the Internet age. In the grassroots league construction in higher vocational colleges, the media is a double-edged sword. On the one hand, the emergence of the media has provided the possibility for grassroots league construction to innovate its own way of work. On the other hand, the rise of media has also led to the diversification of values among young students, resulting in a weak sense of league members. In the face of this situation, how to effectively use the advantages of the media to strengthen the work and avoid the harm that it may bring for the construction, it has become a problem that higher vocational colleges have to face. This paper, starting with the analysis of the characteristics of self media, explores the problems encountered in the construction of higher vocational colleges in the era of self media, and points out some pertinent solutions.
\end{abstract}

The Communist Youth League of China is the most important reserve force of the Communist Party of China. It is an important position for young people to learn Marx doctrine and establish communism belief. As a gathering place for young students, it is an important link between the Communist Party of China and young students. The information explosion brought about by the media age will inevitably impact young students' minds. In this case, how to guide young students to correctly distinguish between right and wrong and to set up a correct value orientation has become a problem that must be solved in the grassroots organizations of higher vocational colleges. However, at present, the relevant research on the use of self media to promote the construction of grassroots league organizations is still in its infancy. Under such circumstances, it is more necessary and important for the higher vocational colleges to carry out relevant research ${ }^{[1]}$.

\section{The Characteristics of Self Media}

In the era of traditional media's popularity, ordinary people want to get information only through newspapers, radio, television and other traditional media. And all kinds of information on media are subject to various restrictions. However, with the advent of the era of media, every citizen has changed from the "spectator" of the incident to the "party" of the incident. For all kinds of events around them, each person can make use of the media, such as text and video, and publish his views on the event. In the era of self media, "media" is no longer a patent for newspapers, radio and television, but also a carrier of personal communication. People can freely express their views in the media and conduct zero distance communication and interaction through the media platform. To sum up, in the era of media, everyone is a grass root journalist and a grass root commentator. He can display himself more freely in the media.

In the operation of traditional media such as television and newspapers, there are a variety of complex workflow. The operation of traditional media needs not only a lot of manpower, material and financial resources, but also the strict examination and approval of relevant departments and permission to operate legally. For ordinary people, these things are hard to come by. However, with the advent of the era of media, it is no longer a dream for ordinary people to build their own "media". At this stage, many websites such as Sina blog and Youku podcast have provided the media platform for ordinary people. On these self media platforms, users only need a simple registration application, according to the network space provided by the service provider and the 
optional template, we can use the layout management tools to publish text, music, pictures, video and other information on the network, and create their own "medium". Compared with traditional media, the media undoubtedly has the access threshold acceptable to ordinary people, and its operation is very simple. Under such circumstances, the form of media has been welcomed by more and more people and made rapid progress[2].

Compared with traditional media, the release of information from the media has broken the limitation of time and space to a certain extent. We must thank the rapid development of Internet technology. In the era of self media, we can publish information at any time or place, or browse and comment on the information released by others. Under such circumstances, the speed of information dissemination has become more rapid, and this speed is difficult to achieve by traditional newspapers, radio or television. In the process of disseminating information from the media, the communicator and the audience can truly achieve "zero distance" communication.

\section{Problems Faced by Grassroots League Construction in Higher Vocational Colleges in the Era of Self Media.}

In China's higher vocational colleges, education reform is in full swing. In the process of educational reform, higher vocational colleges have realized the important role of the grass-roots group construction work to improve students' ideological awareness and moral quality, and also realize that it is imperative to strengthen the work of grass-roots group construction. With the advent of the era of self media, many unexpected changes have taken place in the construction of teaching and League organizations in higher vocational colleges. At this stage, the students in Higher Vocational Colleges in China are mainly post-90s. These students are very capable of accepting new things and are more susceptible to new things such as the self media. In the era of self media, higher vocational colleges have also encountered many problems that have not been encountered before the construction of grass-roots units, which have affected the normal progress of grass-roots group construction work. It can be said that the coming of the media era has both positive and negative effects on the grass-roots League building. Under such circumstances, there must be many new opportunities and challenges for grass-roots League building workers in higher vocational colleges. Facing the new changes brought by the media era, how to use self media to strengthen the work of grass-roots units and avoid the risk brought by the media to the grass-roots group construction work has become an important problem that plagued the organization of higher vocational colleges [3].

With the development of Internet information technology, the Internet age has come quietly. In the Internet era, people's lives depend more and more on the Internet. Among all Internet users, young students occupy a dominant position. In higher vocational colleges, the vast majority of the post-90s students have access to the Internet with mobile phones and notebook computers. As long as they can connect to the network, they can see the figure of the Internet. However, what we must see is that as young students become more and more dependent on the Internet, they are less concerned about other things. Under such circumstances, the "low head group" has gradually become the pronoun of many students who are infatuated with the Internet. In this case, although many students have been in the league, they have no time to care for the development of the group and the life of the group because they are deeply trapped in the network, and do not actively participate in the various studies and activities in the group. Only when the group fee is paid, will they remember the existence of the regiment organization and lack enthusiasm for the organizational life of the participating group. It is precisely because of the lack of life in the League organization that many students nowadays lose their sense of honor and sense of mission, and have a weak sense of organization. Under such circumstances, the grass-roots League Construction in higher vocational colleges can not be carried out effectively [4].

According to the statistics of authoritative survey agencies, we can see that at this stage, China has more than 600 million Internet users. Among the huge Internet users, mobile phone users account for the overwhelming majority. Compared with other countries in the world, this figure is far ahead. However, what we have to see is that the current network is full of all kinds of 
information, which has an impact on the value orientation of the young students who have occupied the majority of the Internet users. Under the influence of various network information, the young students nowadays have shown the tendency of pluralism of values. We must see that due to the lack of effective supervision and supervision mechanism, all kinds of information circulated in our country are mixed. In this information, money worship, hedonism, anarchism and other vulgar cultural garbage, such as pornography and violence, will have a very bad influence on the values of young students. Under such circumstances, the ideological position of the Communist Youth League is at stake. Faced with such problems, most of the League organizations in Higher Vocational Colleges fail to find a good solution. How to bring the idea back to the right track in the diversified values of students' values has become a difficult problem for many vocational colleges.

With the advent of the Internet era, China's network industry has begun to rise. At present, our country already has more than fifty micro-blog and Blog websites. In these websites, the amount of information updated every day is hundreds of millions. And in all kinds of network information, there are not only positive contents, but also many false information and bad information issued by criminals. At present, a considerable portion of the information transmitted by micro-blog and other media in China is rumor, and some rumors even ascend to the traditional media platforms such as newspapers and television, causing serious harm to the society. The students in higher vocational colleges are in the stage of gradually mature values, and lack sufficient social experience and experience. Therefore, they lack sufficient awareness and awareness of bad information and rumors. Under such circumstances, young students are more likely to be misled and deceived by bad information. More serious is, many students in the absence of the true and false situation, the bad information to other students and friends, become the new source of bad information, even by the illegal elements, endangering the safety of the campus. For such a situation, many league organizations in higher vocational colleges are powerless to play a role in helping students distinguish right from wrong. Faced with this problem, the League organization of higher vocational colleges must find a solution as soon as possible, and rescue students from misleading and cheating of all kinds of bad information[5].

\section{Measures to Strengthen Grassroots League Construction in Higher Vocational Colleges in the Era of Self Media}

In the era of self media, the organization of higher vocational colleges should be under the leadership of the party organization in school, to strengthen the construction of the organization of the school - the three class of the class - class, and to carry out the leadership and responsibility system of the group. In the process of carrying out the League organization construction, it is an important means to strengthen the League organization construction in Higher Vocational Colleges in the network age. Taking WeChat as an example, in higher vocational colleges, the group organization should set up a group of WeChat groups with the theme of organizational construction and organization life. In the school, the Group Committee - the group branch - the group branch of the group should be covered by the group. Finally, the WeChat group is included in all the members of the school. In this group of WeChat, in addition to the daily work in the group, it can also carry out the ideological construction and organizational life of the group and explain and train the network knowledge for all the members of the group. At every level of the WeChat group, the leadership responsibility system must be implemented, and the leaders at all levels should be responsible for the management. In this process, the leadership of the group organizations at all levels should carry out the competition mechanism, select the excellent ideological and political quality, and the excellent students with strong language expression and communication ability to participate in the management work, so as to drive all members of the group with the power of example, and then to call all the students to ensure the life of the network group. Quality.

In the new situation, the Central Committee of the Communist Party of China has put forward higher requirements for the moral education of students, and introduced relevant documents to urge the school vacation moral education to guide the students to set up the correct value orientation. Among the students in higher vocational colleges, the only child rate is most. These students are 
weak in feeling, and they like to be self centered in the process of interpersonal communication, and are easy to indulge in the Internet world. All these will adversely affect the physical and mental health of young students. Compared with the reality of silence, students are more willing to speak freely on the Internet. In this case, the organization should actively communicate and communicate "zero distance" with the members of the group with the network as a channel, so as to grasp their ideological trends and understand their real ideas in time, and to communicate with the members of the group for some hot issues in real life, or to solve some of their thoughts. Bewilderment. In the course of communication and communication, once the group leaders find that the members have some new ideas and ideas, or what they do in their lives can carry forward the positive energy, they can carry out vigorous publicity in the group group and build a platform for each group to display themselves, and in the group and the group. A bridge of communication between groups. In this process, the regiment organization can exert influence on the members' minds in a subtle way, and guide their values into the right direction [6].

\section{Using Self Media to Innovate the Work Style of the League Organization.}

For a long time, the traditional regiment organization life has always been learning documents, meetings, visiting revolutionary shrines and voluntary labor. In the long term organization construction, the content of these activities is less and less attractive to young students, and it can play a limited role in solving the ideological problems of Youth League members. In the face of such problems, the organization of higher vocational colleges must emancipate their minds and provide the members and all the students with their best service while using the network media for the construction of the group. For example, in the WeChat group of the League organization, in addition to publishing related contents of the regiment organization's life, it can also publish some students' learning and life information. For example, in WeChat, the 46 level of English test time, examination rules and other information can be published, and some second-hand goods and lost and found information, which are closely related to the life of the students, can be published, so that the Youth League members are more effectively united in the group organization, and the organization construction of the group is strengthened.

\section{Summary}

To sum up, the arrival of the media era has brought far-reaching influence on the organizational construction of the grass-roots group in higher vocational colleges, and the grass-roots organizations in higher vocational colleges will change the traditional way of work. In the construction of the organizational structure of the grass-roots group under the new situation, the organization of the higher vocational college should not only see the negative influence of the media to the young students, but also the positive role that it can play to the construction of the group, and make use of it effectively, so as to strengthen the communication and communication with the students in the age of the media. The values of the students lead to the correct direction, and in the actual work to deepen the group's influence on the students, and then strengthen the organizational construction of the higher vocational colleges.

\section{Acknowledgment}

Foundation project: Research on the innovative grass-roots group construction mode of Art Vocational Colleges under the background of big data (provincial level), project number: 2018JS600

\section{References}

[1] Xu X G. Social Rationality and Perspective Conversion of Urban Grassroots Governance Socialization- Based on the Practice of “CSS Cooperation"in Shanghai Mei Village[J]. Social 
Construction, 2017.

[2] Wang H, Gong X, Deng L, et al. Discussion on Chinese Medicine in the Development of Grassroots from the "Practice of Medical Service"[J]. Chinese Medicine Modern Distance Education of China, 2016.

[3] Yu S, Marxism S O, University S. On Essence of the Grassroots Self- Government Based on the Practice of the Y Community[J]. Journal of Jixi University, 2016.

[4] Luo J L. Combination Campaign: Inspiration from the Practice of Grassroots Democracy in Tengyun County[J]. Journal of Xiangfan University, 2016, 107(23):10344-10347.

[5] Liang Y Z. Thoughts on strengthening the construction of grass roots Party organizations in higher vocational colleges[J]. Journal of Jiamusi Vocational Institute, 2017.

[6] Jiao B, Zhang X. Research on the promotion path of class league branch construction in higher vocational colleges[J]. Journal of Shaanxi Youth Vocational College, 2017.

Introduction: Cai Niekui (1981.05.24), male, Han, Yunnan Ma Guan, university lecturer, undergraduate, mainly engaged in computer teaching, student management 